\title{
Effects of La and Ce Addition on the Modification of Al-Si Based Alloys
}

\author{
Emad M. Elgallad, ${ }^{1}$ Herbert W. Doty, ${ }^{2}$ Saleh A. Alkahtani, ${ }^{3}$ and Fawzy H. Samuel ${ }^{1}$ \\ ${ }^{1}$ Université du Québec à Chicoutimi, Chicoutimi, QC, Canada G7H $2 B 1$ \\ ${ }^{2}$ General Motors Materials Engineering, Pontiac, MI, USA \\ ${ }^{3}$ Industrial Engineering Program, Mechanical Engineering Department, College of Engineering, \\ Sattam Bin Abdulaziz University, Al Kharj, Saudi Arabia \\ Correspondence should be addressed to Fawzy H. Samuel; fhsamuel@uqac.ca
}

Received 29 December 2015; Revised 14 February 2016; Accepted 30 March 2016

Academic Editor: Jörg M. K. Wiezorek

Copyright (C) 2016 Emad M. Elgallad et al. This is an open access article distributed under the Creative Commons Attribution License, which permits unrestricted use, distribution, and reproduction in any medium, provided the original work is properly cited.

\begin{abstract}
This study focuses on the effects of the addition of rare earth metals (mainly lanthanum and cerium) on the eutectic Si characteristics in Al-Si based alloys. Based on the solidification curves and microstructural examination of the corresponding alloys, it was found that addition of La or Ce increases the alloy melting temperature and the Al-Si eutectic temperature, with an Al-Si recalescence of $2-3^{\circ} \mathrm{C}$, and the appearance of post- $\alpha$-Al peaks attributed to precipitation of rare earth intermetallics. Addition of La or Ce to Al-(7-13)\% Si causes only partial modification of the eutectic Si particles. Lanthanum has a high affinity to react with Sr, which weakens the modification efficiency of the latter. Cerium, however, has a high affinity for Ti, forming a large amount of sludge. Due to the large difference in the length of the eutectic Si particles in the same sample, the normal use of standard deviation in this case is meaningless.
\end{abstract}

\section{Introduction}

Nafisi et al. [1] studied the nucleation mechanism of eutectic grains in hypoeutectic Al-Si alloys. They proposed that, following nucleation of eutectic $\mathrm{Al}$ on the primary $\alpha$-Al dendrites, fine Si particles form at the solidification front upon which the eutectic Si flakes and fibers could develop. The formation of small $\mathrm{Si}$ particles is attributed to $\mathrm{Si}$ enrichment of the remaining melt due to the formation of eutectic $\mathrm{Al}$ (aluminum spikes) at the eutectic temperature. It has been proposed that modification of eutectic silicon by trace additions occurs due to a massive increase in the twin density caused by atomic effects at the growth interface [2]. Although the discovery of the modification effect dates back to 1921 [3], the exact mechanism of eutectic medication is not completely understood. The high twin density in Si fibers would require $\mathrm{Sr}$ atoms to be distributed rather uniformly within the $\mathrm{Si}$ phase. Besides the effect of $\mathrm{Sr}$ addition on the growth of eutectic Si, recent studies have confirmed that $\mathrm{Sr}$ also changes significantly the nucleation behavior of the eutectic phases [4]. The elements causing modification have an atomic radius ratio close to 1.65 from the theory of impurity induced twinning (IIT), and the fine fibrous eutectic modifications of hypoeutectic Al-7\%Si alloys containing $\mathrm{Sr}$, $\mathrm{Na}, \mathrm{Ca}$, and $\mathrm{Ba}$ have all been investigated. The addition of rare earth elements $\mathrm{La}, \mathrm{Sm}$, and Ce was also reported to cause eutectic modification [5].

Strontium, sodium, calcium, and antimony are added to eutectic or hypoeutectic Al-Si casting alloys to modify the morphology and microstructure of the eutectic silicon phase from its usual relatively coarse continuous network of thin platelets in the unmodified as-cast structure [6]. Modification with one of these elements can change or "modify" the eutectic silicon into a fine fibrous or lamellar structure [7]. The hypothesis that $\mathrm{Sr}$ additions cause modification by increasing the growth rate of the eutectic has been tested by directionally solidifying unmodified and $\mathrm{Sr}$-modified alloys [8]. It was found that Sr-modified alloys have a smaller eutectic spacing than unmodified alloys, even when both are grown at identical velocities [9]. 
The modifying action of many rare earth metals in an Al-10 mass\% Si alloy was investigated by Nogita et al. [11], where all rare earth elements had some effect on the eutectic silicon. Among them, europium was the only element which produced a fully modified, fine fibrous silicon structure. The other elements provided only a minor refinement of the plate-like silicon morphology. Pourbahari et al. [12] studied the effects of La addition and heat treatment on the microstructure and tensile properties of A357 aluminum alloy. Their results showed that the addition of La obviously reduced the size and area of eutectic silicon particles after heat treatment. New intermetallics were detected at higher La levels $(>0.5 \%)$. The effects of $\mathrm{Ce}$ and $\mathrm{La}$ on microstructure and properties of a $6 \mathrm{xxx}$ series type aluminum alloy were investigated by Hosseinifar and Malakhov [13]. They found that, in alloys containing $0.1-0.2 \mathrm{wt}$.\% of La, the fraction of $\beta-\mathrm{Al}_{5} \mathrm{FeSi}$ particles was pronouncedly less than that in the base alloy. In addition to this advantage, much smaller grains were seen in the alloy containing $0.2 \mathrm{wt}$. \% La. On the other hand, $\mathrm{Ce}$ addition neither modified the microstructure nor noticeably affected the grain size.

According to Hosseinifar and Malakov [13, 14], the intermetallics formed during the solidification of an Al$\mathrm{Mg}-\mathrm{Si}$ alloy containing La may be proposed as follows: the addition of $\mathrm{La}$ results in the formation of the $\mathrm{La}(\mathrm{Al}, \mathrm{Si})_{2}$ phase and a depletion of $\mathrm{Si}$ in the remaining melt. It is hypothesized that the decreased $\mathrm{Si} / \mathrm{Fe}$ ratio in the melt caused by the presence of La favors the formation of the $\alpha$-AlFeSi phase, which is less detrimental to the formability of the alloy than the $\beta$-AlFeSi phase. The work of Tsaia et al. [15] on the effect of trace $\mathrm{Ce}$ additions on the microstructure and mechanical properties of A356 (Al-7Si-0.35 Mg) aluminum alloy indicates that modification efficiency and hence mechanical properties of A356 alloy are greatly enhanced by adding 1.0 wt.\% Ce. Two kinds of intermetallic compounds were reported in their study, including Ce-23\%Al-22\%Si and $\mathrm{Al}-17 \% \mathrm{Ce}-12 \% \mathrm{Ti}-2 \% \mathrm{Si}-2 \% \mathrm{Mg}$ (all percentages are in wt.\%) phases. In addition, Ce improved the thermal stability of the $\Omega$ phase by decreasing the diffusion velocity of $\mathrm{Cu}$ atoms and increasing the energy barrier of the thickening ledge nucleation, thus improving the strength of the Al-Cu-Mg-Ag alloy at both room and elevated temperatures [16].

In the present work, A356 and 413 alloys were selected for study, being two commercially popular Al-Si alloys. These alloys are also in high demand in the automotive industry which is the largest consumer of cast Al-Si alloys. The 356 alloy is a hypoeutectic alloy, whereas the 413 alloy is a eutectic alloy. As the microstructure of Al-Si alloys, in particular the eutectic Si morphology, considerably influences the mechanical properties, modification of the eutectic Si was investigated, using both strontium ( $\mathrm{Sr}$ ) and rare earth (RE) metals. While strontium is commonly used in foundries as the modifying agent, the use of mischmetal (MM) or rare earth metals as modifiers for Al-Si alloys has also been reported in the literature, where mischmetal consists of a mixture of rare earth metals. In the present study, the effect of each modifier type and possible interactions between them were investigated to arrive at a better understanding of their influence on the microstructure of these two alloys.
TABLE 1: Chemical composition of the base alloys used in the present study.

\begin{tabular}{lcccccc}
\hline Alloy & \multicolumn{7}{c}{ Elements (wt\%) } \\
Alloy codes & $\mathrm{Si}$ & $\mathrm{Cu}$ & $\mathrm{Mg}$ & $\mathrm{Fe}$ & $\mathrm{Zn}$ & $\mathrm{Al}$ \\
\hline A356 & 7 & $<0.20$ & $<0.35$ & $<0.20$ & $<0.10$ & $\mathrm{Bal}$ \\
T0* $^{*}$ T0S** & & & & & & \\
413 & 12 & $<0.10$ & $<0.10$ & $<0.20$ & $<0.1$ & $\mathrm{Bal}$ \\
E0 $^{*}$, E0S $^{* *}$ & 12 & & & & & \\
\hline
\end{tabular}

${ }^{*}$ Nonmodified and ${ }^{* *}$ modified with $\sim 70 \mathrm{ppm} \mathrm{Sr}$.

\section{Experimental Procedure}

The compositions of the A356 and 413 ingots used in the present study are shown in Table 1.

In order to modify the eutectic silicon, strontium and the rare earth metals lanthanum and cerium were used as modifying agents. These were added to the alloy melts in the form of $\mathrm{Al}-10 \% \mathrm{Sr}, \mathrm{Al}-10 \% \mathrm{La}$, and $\mathrm{Al}-11 \% \mathrm{Ce}$ master alloys, respectively, in the amounts required to achieve the desired additions.

The A356 (or 413) ingots ( $12 \mathrm{~kg}$ charges) were cut into smaller pieces, cleaned, dried, and then melted in a $\mathrm{SiC}$ crucible, using an electric resistance furnace. The melt temperature was kept at $750^{\circ} \pm 5^{\circ} \mathrm{C}$. The melt was degassed using pure, dry argon injected by means of a rotary impeller (for 8$10 \mathrm{~min}$ at $120 \mathrm{rpm}$ ). Modifier additions of Sr, La, and Ce were made for each alloy as follows:

$$
\begin{aligned}
& \text { Sr: } 0 \text { and } 0.01 w t \% . \\
& \text { La: } 0,0.2,0.5,1 \text {, and } 1.5 w t \% \text {. } \\
& \text { Ce: } 0,0.2,0.5,1 \text {, and } 1.5 w t \% \text {. }
\end{aligned}
$$

Besides being added individually, modifiers were also added in combinations of $\mathrm{La}+\mathrm{Ce}, \mathrm{La}+\mathrm{Sr}, \mathrm{Ce}+\mathrm{Sr}$, and $\mathrm{La}+$ $\mathrm{Ce}+\mathrm{Sr}$ as follows:

$$
\begin{aligned}
& \text { La + Ce: } 0.5+0.5 ; 1+1 ; \text { and } 1.5+1.5 \text { wt } \% \text {. } \\
& \text { La + Sr: } 0.2+0.01 ; 0.5+0.01 ; 1+0.01 ; \text { and } 1.5+ \\
& 0.01 \text { wt } \% \text {. } \\
& \text { Ce + Sr: } 0.2+0.01 ; 0.5+0.01 ; 1+0.01 ; \text { and } 1.5+ \\
& 0.01 \text { wt } \% \text {. } \\
& \text { La + Ce + Sr: } 0.5+0.5+0.01 ; 1+1+0.01 ; \text { and } 1.5+1.5 \\
& +0.01 \text { wt } \% \text {. }
\end{aligned}
$$

For each casting poured from the different melts, samplings for chemical analysis were also taken. The modifier additions obtained from the chemical analyses and the corresponding alloy codes are shown in Tables 2 and 3. A schematic diagram of the graphite mold used in the present study is shown in Figure 1. The mold was preheated at $600^{\circ} \mathrm{C}$ to obtain cooling rates close to equilibrium conditions. Thermal analysis for the graphite mold casting was performed by attaching a high-sensitivity thermocouple (chromel-alumel, type $\mathrm{K}$ ) to the mold system, passing through the bottom of the mold and extending half way up into the mold cavity along the mold centreline. The temperature-time data were recorded using a high-speed $(0.2 \mathrm{sec})$ data acquisition system 
TABLE 2: Modifier additions and corresponding alloy codes for A3356 alloy.

\begin{tabular}{|c|c|c|c|c|c|c|}
\hline \multirow{3}{*}{ Alloy } & \multirow{3}{*}{ Mold type } & \multirow{3}{*}{ Mold temperature $\left({ }^{\circ} \mathrm{C}\right)$} & \multirow{3}{*}{ Alloy code } & \multicolumn{3}{|c|}{ Modifier addition (wt\%) } \\
\hline & & & & & Actua & \\
\hline & & & & $\mathrm{Sr}$ & $\mathrm{La}$ & $\mathrm{Ce}$ \\
\hline \multirow{23}{*}{356} & \multirow{23}{*}{ Graphite } & \multirow{23}{*}{600} & $\mathrm{~TB}$ & 0 & 0 & 0 \\
\hline & & & $\mathrm{T} 10$ & 0 & 0.165 & 0 \\
\hline & & & $\mathrm{T} 1$ & 0 & 0.356 & 0 \\
\hline & & & $\mathrm{T} 2$ & 0 & 0.685 & 0 \\
\hline & & & $\mathrm{T} 3$ & 0 & 1.025 & 0 \\
\hline & & & T11 & 0 & 0.032 & 0.082 \\
\hline & & & $\mathrm{T} 4$ & 0 & 0.136 & 0.185 \\
\hline & & & T5 & 0 & 0.046 & 0.317 \\
\hline & & & T6 & 0 & 0.089 & 1.088 \\
\hline & & & $\mathrm{T} 7$ & 0 & 0.44 & 0.282 \\
\hline & & & $\mathrm{T} 8$ & 0 & 0.781 & 0.377 \\
\hline & & & T9 & 0 & 1.073 & 0.531 \\
\hline & & & T10S & 0.0069 & 0.165 & 0 \\
\hline & & & T1S & 0.0109 & 0.356 & 0 \\
\hline & & & $\mathrm{T} 2 \mathrm{~S}$ & 0.0047 & 0.685 & 0 \\
\hline & & & T3S & 0.0047 & 1.025 & 0 \\
\hline & & & T11S & 0.0073 & 0.032 & 0.082 \\
\hline & & & $\mathrm{T} 4 \mathrm{~S}$ & 0.007 & 0.136 & 0.185 \\
\hline & & & T5S & 0.0061 & 0.046 & 0.317 \\
\hline & & & T6S & 0.006 & 0.089 & 1.088 \\
\hline & & & T7S & 0.006 & 0.44 & 0.282 \\
\hline & & & T8S & 0.0053 & 0.781 & 0.377 \\
\hline & & & T9S & 0.006 & 1.073 & 0.531 \\
\hline
\end{tabular}

TABLE 3: Modifier additions and corresponding alloy codes for 413 alloy.

\begin{tabular}{|c|c|c|c|c|c|c|}
\hline \multirow{3}{*}{ Alloy } & \multirow{3}{*}{ Mold type } & \multirow{3}{*}{ Mold temperature $\left({ }^{\circ} \mathrm{C}\right)$} & \multirow{3}{*}{ Alloy code } & \multicolumn{3}{|c|}{ Modifier addition (wt\%) } \\
\hline & & & & \multicolumn{3}{|c|}{ Actual } \\
\hline & & & & $\mathrm{Sr}$ & $\mathrm{La}$ & $\mathrm{Ce}$ \\
\hline \multirow{23}{*}{413} & \multirow{23}{*}{ Graphite } & \multirow{23}{*}{600} & TE & 0 & 0 & 0 \\
\hline & & & TE10 & 0 & 0.165 & 0 \\
\hline & & & TE1 & 0 & 0.356 & 0 \\
\hline & & & TE2 & 0 & 0.685 & 0 \\
\hline & & & TE3 & 0 & 1.025 & 0 \\
\hline & & & TE11 & 0 & 0.032 & 0.082 \\
\hline & & & TE4 & 0 & 0.136 & 0.185 \\
\hline & & & TE5 & 0 & 0.046 & 0.317 \\
\hline & & & TE6 & 0 & 0.089 & 1.088 \\
\hline & & & TE7 & 0 & 0.44 & 0.282 \\
\hline & & & TE8 & 0 & 0.781 & 0.377 \\
\hline & & & TE9 & 0 & 1.073 & 0.531 \\
\hline & & & TE10S & 0.0078 & 0.165 & 0 \\
\hline & & & TE1S & 0.0087 & 0.356 & 0 \\
\hline & & & TE2S & 0.0065 & 0.685 & 0 \\
\hline & & & TE3S & 0.0079 & 1.025 & 0 \\
\hline & & & TE11S & 0.0193 & 0.032 & 0.082 \\
\hline & & & TE4S & 0.0123 & 0.136 & 0.185 \\
\hline & & & TE5S & 0.0071 & 0.046 & 0.317 \\
\hline & & & TE6S & 0.008 & 0.089 & 1.088 \\
\hline & & & TE7S & 0.0079 & 0.44 & 0.282 \\
\hline & & & TE8S & 0.0084 & 0.781 & 0.377 \\
\hline & & & TE9S & 0.0071 & 1.073 & 0.531 \\
\hline
\end{tabular}




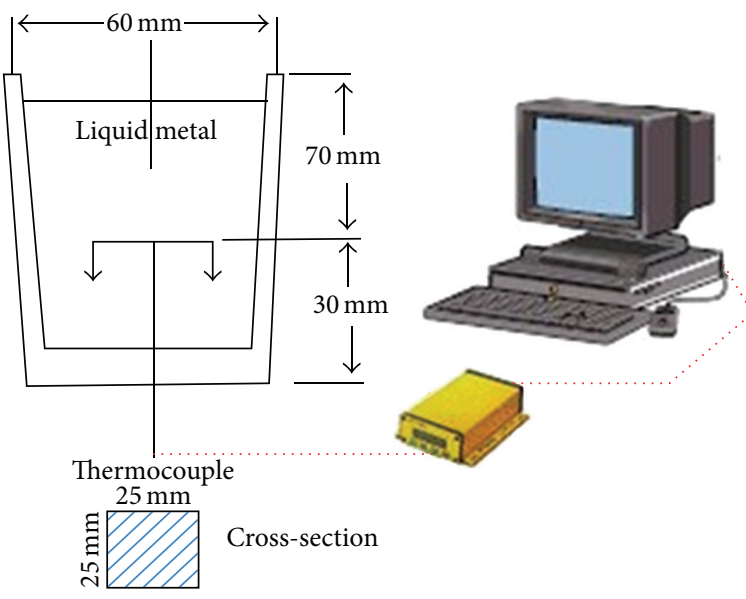

FIGURE 1: Graphite mold and data acquisition system used in the present study.

linked to a computer. The part of the thermocouple within the mold was protected using double-walled ceramic tubing. From the thermal analysis data, the cooling curves and their first derivatives were plotted and analyzed.

In order to study the effect of the modifiers employed on the silicon particle characteristics of the A356 and 413 alloys, samples $(2 \times 2 \mathrm{~cm})$ were sectioned from each of the castings ( $30 \mathrm{~mm}$ from the bottom) for metallographic examination. The polished samples were examined under an optical microscope (Olympus BH2-UMA). A Clemex image analyzer system was used in conjunction with the optical microscope for quantitative analysis of the silicon particle characteristics. In each case, the measurements were carried out over fifty fields (at 200x magnification) such that the entire sample surface was traversed in a regular, systematic fashion to obtain the average values of each of the measured parameters. Element distribution in some intermetallics was examined using a Hitachi-SU 8000 FESEM microscope equipped with an energy dispersive X-ray (EDS) system. Compositional analyses of the intermetallic phases detected in the present work and phase identification were carried out by employing an electron probe microanalysis- (EPMA-) Jeol model JXA$8900 \mathrm{R}$, operating at $20 \mathrm{kV}$ and $30 \mathrm{nA}$, with an electron beam size of $\sim 1 \mu \mathrm{m}$ coupled with energy dispersive X-ray (EDS) and wavelength dispersion spectroscopic (WDS) analyses.

\section{Results and Discussion}

3.1. Solidification Curves. Dobrzański et al. [17] studied the effect of solidification/cooling rate on alloy thermal characteristics in cast $\mathrm{Al}-\mathrm{Si}-\mathrm{Cu}$ alloy. The authors concluded that the solidification parameters are affected by the cooling rate. The formation temperatures of various phases are changed with an increase in cooling rate. A thermal analysis study of the simultaneous grain refinement and modification of 380.3 aluminum alloy was carried out by Malekan et al. [8]. The results show that eutectic Si modification due to the addition of Al-10Sr-1Ti-2B was found to be correlated to the depression of the aluminum-silicon eutectic growth

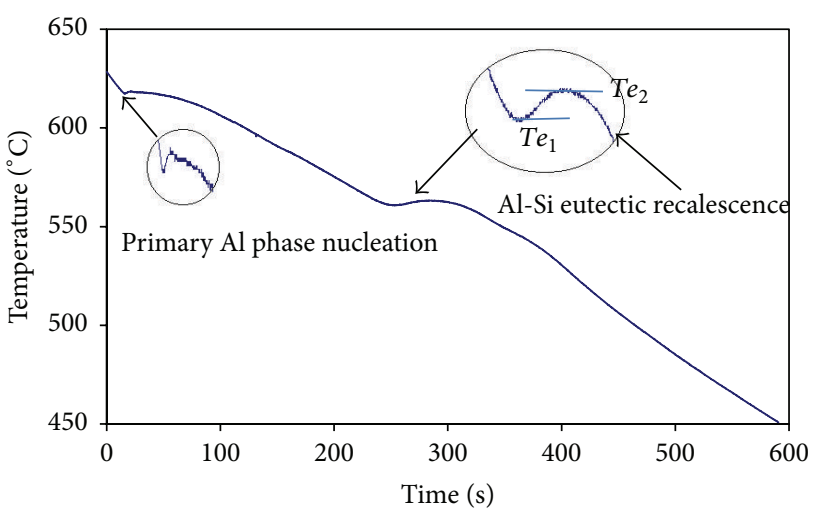

Figure 2: Al-Si eutectic recalescence in a binary Al-7\% $\mathrm{Si}$ alloy, $\mathrm{Te}_{1}$ $=T_{\mathrm{M}}$ temperature, and $T e_{2}=T_{\mathrm{G}}$ temperature [10].

temperature, $\Delta T_{\mathrm{Al}-\mathrm{Si}}$, that is controlled by the Al-10Sr-1Ti$2 \mathrm{~B}$ content. Therefore, the thermal analysis measurement of $\Delta T_{\mathrm{Al}-\mathrm{Si}}$ can be used for online prediction of modification of eutectic Si.

Solidification kinetics of an unmodified and Sr-modified near-eutectic Al-Si alloy were analyzed by Aparicio et al. [18] who found that there are changes in the solidification rate during eutectic nucleation followed by similar solidification rate evolutions during growth, suggesting that this parameter is governed principally by the heat extraction conditions. The work of Hengcheng et al. [10] on the effects of $\mathrm{Sr}$ and solidification rate on eutectic grain structure in an $\mathrm{Al}-$ $13 \mathrm{wt} \% \mathrm{Si}$ alloy revealed that the characteristic temperature of eutectic nucleation $\left(T_{\mathrm{N}}\right)$, the minimum temperature prior to recalescence $\left(T_{\mathrm{M}}\right)$, and the growth temperature $\left(T_{\mathrm{G}}\right)$ during cooling as determined by quantitative thermal analysisare continuously decreased with increasing Sr content. As mentioned previously, Nogita et al. [11] reported that all rare earth elements had some effect on the eutectic silicon; however, europium was the only element to cause fully modified, fine fibrous silicon, whereas the other elements only produced a minor refinement of the plate-like silicon morphology.

Figure 2 is a typical solidification curve obtained at a very slow rate $\left(\sim 0.8^{\circ} \mathrm{C} / \mathrm{s}\right)$ illustrating $\mathrm{Al}-\mathrm{Si}$ eutectic recalescence [19]. In the present study, analysis will only focus on the $\mathrm{Al}-\mathrm{Si}$ eutectic reaction. When $\mathrm{Mg}$ is added to the $\mathrm{Al}-7 \% \mathrm{Si}$ alloy, Figure 3(a), precipitation of $\mathrm{Mg}_{2} \mathrm{Si}$ takes place at about $550^{\circ} \mathrm{C}$ [20]. Addition of rare earth metals (RE) to this alloy, Figure 3(b), resulted in (a) increasing the alloy melting temperature, (b) formation of $\mathrm{Al}-\mathrm{Si}$ eutectic recalescence, (c) a slight decrease in the eutectic temperature $\left(\sim 2-3^{\circ} \mathrm{C}\right)$, and (d) precipitation of several intermetallic phases following the precipitation of the $\alpha$-Al dendritic network. It should be emphasized here that the precipitation temperatures of REcontaining alloys have not been reported in the literature.

Elsebaie et al. [21-23] studied the precipitation of intermetallic phases observed in nonmodified and Sr-modified A319, A356, and A413 Al-Si based cast alloys containing mischmetals (MM), using wavelength dispersion spectroscopic analysis to identify these phases. In addition to the $\mathrm{Al}_{2} \mathrm{Cu}$ phase in $\mathrm{A} 319$ alloy, the $\mathrm{Mg}_{2} \mathrm{Si}$ phase in A356 alloy, 


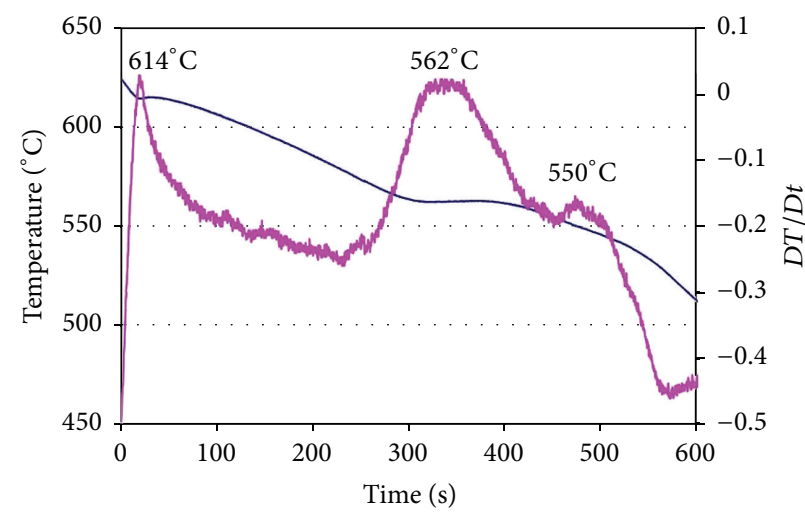

(a)

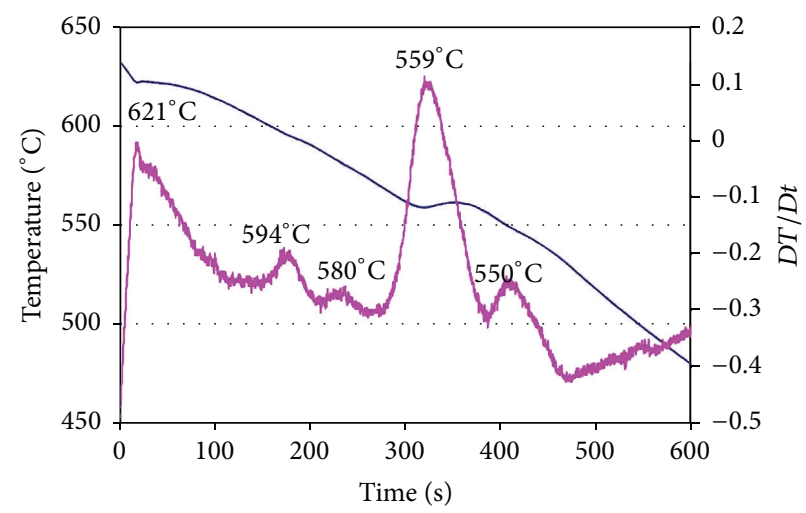

(b)

FIgURE 3: Solidification curve and the first derivative for (a) T0 alloy and (b) T9 alloy.

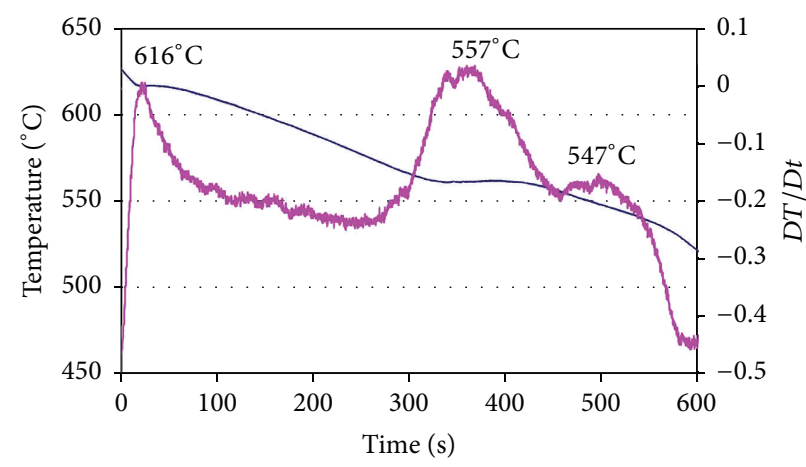

(a)

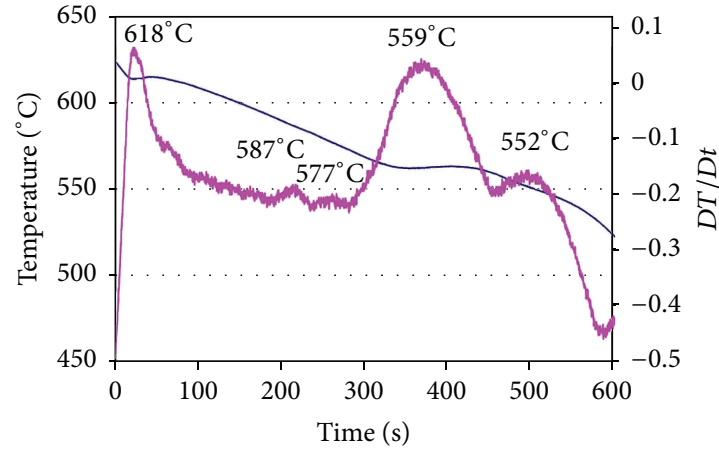

(b)

Figure 4: Solidification curve and the first derivative for (a) T0S alloy and (b) T9S alloy.

and the platelet-like $\beta-\mathrm{Al}_{5} \mathrm{FeSi}$ and $\alpha-\mathrm{Al}_{15}(\mathrm{MnFe})_{3} \mathrm{Si}_{2}$ and $\alpha$ $\mathrm{Al}_{15}(\mathrm{MnFeNiCu})_{3} \mathrm{Si}_{2}$ Chinese script-like iron intermetallic phases in the A413 alloy, various MM-containing intermetallic phases were observed at high and low cooling rates, each exhibiting a specific Ce/La ratio and morphology. Many of these MM-containing intermetallic phases were found to contain $\mathrm{Sr}$, which confirmed the interaction of mischmetal with strontium (Sr). Thus, the effectiveness of $\mathrm{Sr}$ as a modifier of the eutectic Si phase in these alloys would be reduced.

Figure 4(a) presents the solidification curve of TOS alloy revealing the depression in the $\mathrm{Al}-\mathrm{Si}$ eutectic temperature by about $3^{\circ} \mathrm{C}$ with the addition of $70 \mathrm{ppm} \mathrm{Sr}$ to T0 alloy [24]. Addition of RE to TOS alloy, for example, T9S alloy (Figure 4(b)), resulted in similar behavior as exhibited by the T9 alloy. The eutectic temperature, however, was increased by $2^{\circ} \mathrm{C}$ compared to TOS alloy, indicating an RE-Sr interaction [23] leading to the expected degradation of the modification effect of the added strontium.

The influence of strontium addition and solidification rate on eutectic structure in a near-eutectic $\mathrm{Al}-13 \% \mathrm{Si}$ alloy was investigated. The characteristic temperature of eutectic nucleation $\left(T_{\mathrm{N}}\right)$, minimum temperature prior to recalescence $\left(T_{M}\right)$, and the growth temperature $\left(T_{G}\right)$ during cooling were determined by quantitative thermal analysis. All characteristic temperatures were found to decrease continuously with increasing Sr content and solidification rate [10]. Ferdian et al. [25] studied the effect of various cooling rates on eutectic modification in Sr-modified A356 alloy, using sand and metallic molds. An assessment of eutectic modification was made based on data obtained from cooling curves recorded from thermocouples inserted in the centre of the samples to determine the parameters associated with Al-Si eutectic reaction in each case. In addition to the parameters noted in Figure 2, the eutectic depression or eutectic growth undercooling $\left(T_{R}-T_{G}\right)$ was defined as the difference between the equilibrium eutectic temperature $T_{R}$ and the actual eutectic temperature, $T_{\mathrm{G}}$, where $T_{\mathrm{R}}$ is calculated using a modified version of the equation proposed by Mondolfo [26] for AlSi alloys, using $12.5 \mathrm{wt} . \% \mathrm{Si}$ and $577^{\circ} \mathrm{C}$ as representing the eutectic reaction in the binary Al-Si alloy:

$$
\begin{aligned}
& T_{\mathrm{R}}\left({ }^{\circ} \mathrm{C}\right)=577-\left(\frac{12.5}{\mathrm{wSi}}\right) *(4.59 * \mathrm{wMg}+1.37 * \mathrm{wFe} \\
& \quad+1.65 * \mathrm{wCu}+0.35 * \mathrm{wZn}+2.54 * \mathrm{wMn}+3.52 \\
& \quad * \mathrm{wNi}) .
\end{aligned}
$$

In the present work, although the introduction of rare earths led to an increase in both melting and eutectic temperatures (Figures 5 and 6), no noticeable recalescence was observed in the 413 alloys. Table 4 and Figure 7 display 


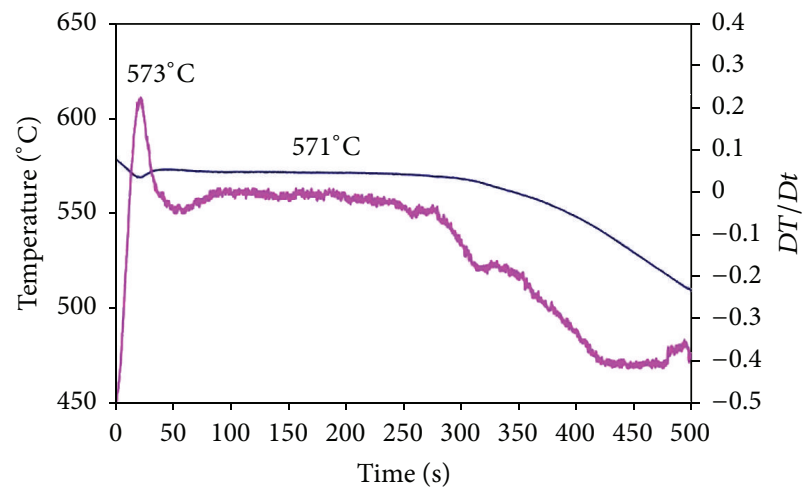

(a)

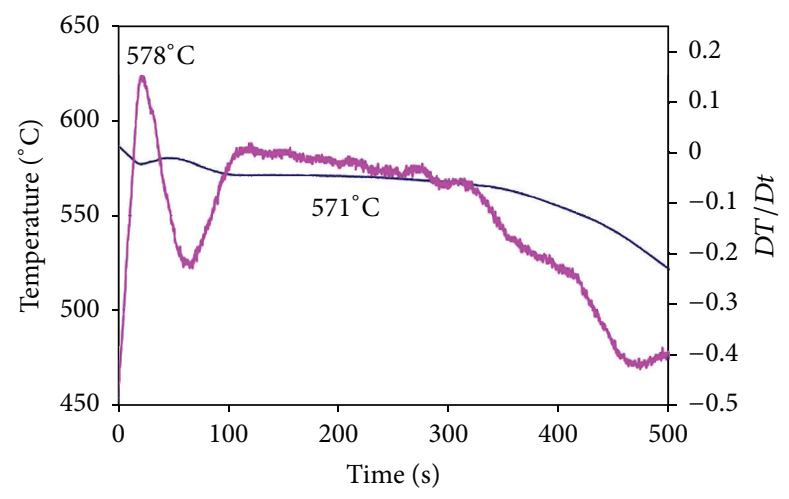

(b)

FIgURE 5: Solidification curve and first derivative for (a) E0 alloy and (b) E9 alloy.

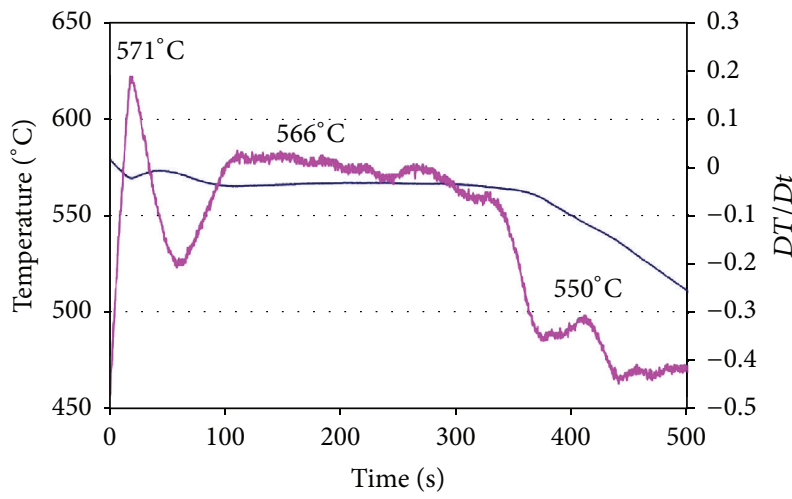

(a)

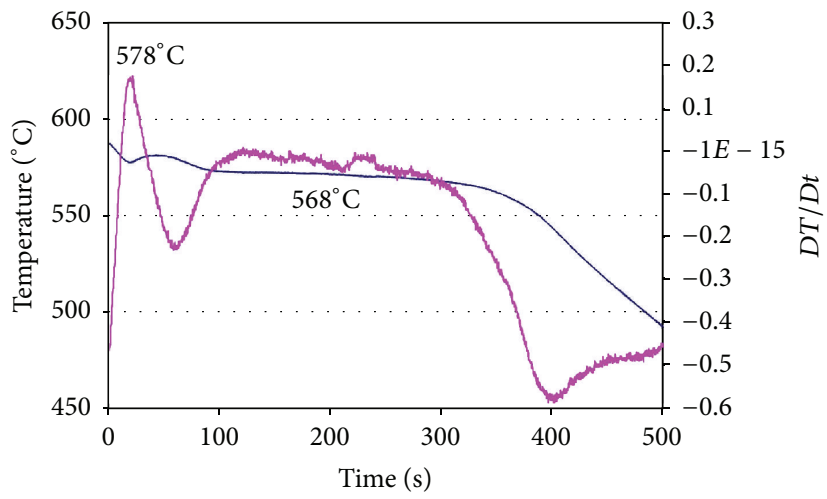

(b)

FIGURE 6: Solidification curve and first derivative for (a) E0S alloy and (b) E9S alloy.

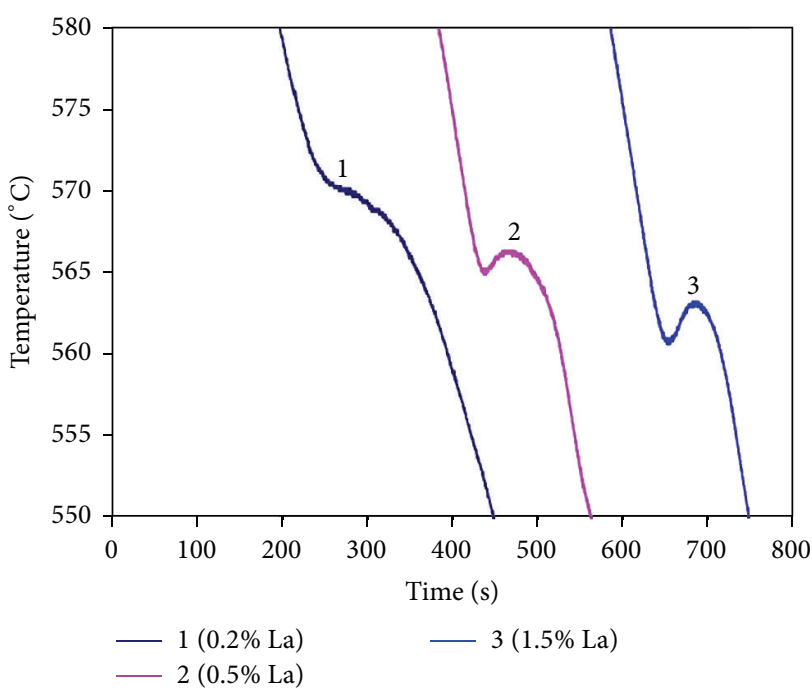

(a)

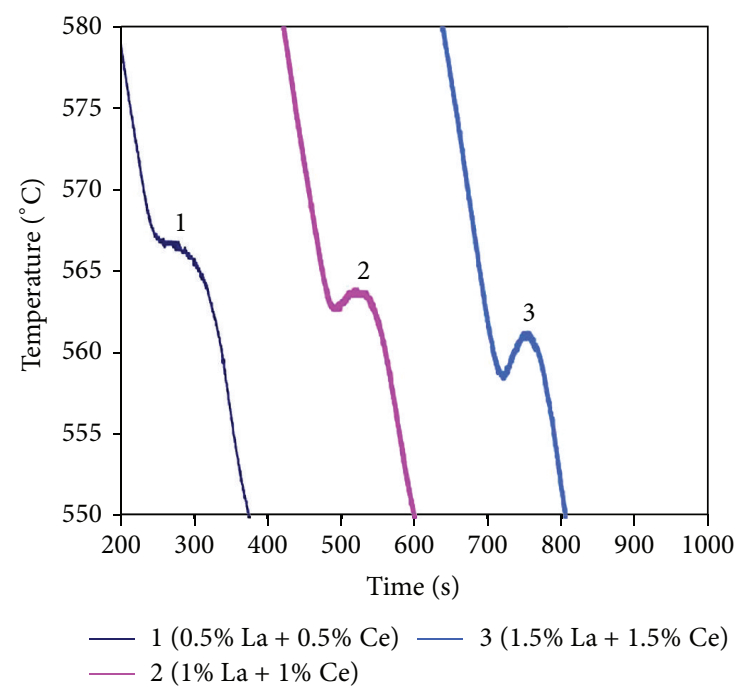

(b)

FIGURE 7: Examples of Al-Si eutectic undercooling in 356 alloy after (a) La and (b) La + Ce additions. 
TABLE 4: (a) Effect of La on recalescence observed in 356 alloy. (b) Effect of Ce on recalescence observed in 356 alloy. (c) Effect of La and Ce on recalescence observed in 356 alloy.

(a)

\begin{tabular}{|c|c|c|c|c|c|c|c|c|c|c|}
\hline \multirow{3}{*}{ Alloy code } & \multicolumn{4}{|c|}{ Composition } & \multicolumn{6}{|c|}{ Recalescence of eutectic solidification } \\
\hline & \multicolumn{2}{|c|}{ Aimed } & \multicolumn{2}{|c|}{ Actual } & \multirow{2}{*}{$T e_{1}$} & \multirow{2}{*}{$\mathrm{Te}_{2}$} & \multirow{2}{*}{$\Delta T e$} & \multirow{2}{*}{$t e_{1}$} & \multirow{2}{*}{$t e_{2}$} & \multirow{2}{*}{$\Delta t e$} \\
\hline & $\mathrm{La}($ wt $\%)$ & $\mathrm{Ce}(\mathrm{wt} \%)$ & $\mathrm{La}$ (wt $\%$ ) & $\mathrm{Ce}(\mathrm{wt} \%)$ & & & & & & \\
\hline T10 & 0.2 & 0 & 0.17 & 0 & 570.0 & 570.0 & 0 & 0 & 0 & 0 \\
\hline $\mathrm{T} 1$ & 0.5 & 0 & 0.36 & 0 & 565.2 & 566.4 & 1.3 & 239.8 & 260.2 & 20.4 \\
\hline T3 & 1.5 & 0 & 1.25 & 0 & 560.9 & 563.2 & 2.0 & 257.0 & 281.2 & 24.2 \\
\hline
\end{tabular}

(b)

\begin{tabular}{|c|c|c|c|c|c|c|c|c|c|c|}
\hline \multirow{3}{*}{ Alloy code } & \multicolumn{4}{|c|}{ Composition } & \multicolumn{6}{|c|}{ Recalescence of eutectic solidification } \\
\hline & \multicolumn{2}{|c|}{ Aimed } & \multicolumn{2}{|c|}{ Actual } & \multirow{2}{*}{$T e_{1}$} & \multirow{2}{*}{$T e_{2}$} & \multirow{2}{*}{$\Delta T e$} & \multirow{2}{*}{$t e_{1}$} & \multirow{2}{*}{$t e_{2}$} & \multirow{2}{*}{$\Delta t e$} \\
\hline & $\mathrm{La}($ wt $\%)$ & $\mathrm{Ce}(\mathrm{wt} \%)$ & $\mathrm{La}($ wt $\%)$ & $\mathrm{Ce}(\mathrm{wt} \%)$ & & & & & & \\
\hline T11 & 0 & 0.2 & 0 & 0.08 & 562.1 & 562.8 & 0.7 & 326.8 & 367.0 & 40.2 \\
\hline $\mathrm{T} 4$ & 0 & 0.5 & 0 & 0.39 & 566.8 & 567.5 & 0.7 & 257.4 & 280.4 & 23.0 \\
\hline T5 & 0 & 1.0 & 0 & 0.82 & 566.2 & 566.8 & 0.6 & 255.0 & 277.2 & 22.2 \\
\hline
\end{tabular}

(c)

\begin{tabular}{|c|c|c|c|c|c|c|c|c|c|c|}
\hline \multirow{3}{*}{ Alloy code } & \multicolumn{4}{|c|}{ Composition } & \multicolumn{6}{|c|}{ Recalescence of eutectic solidification } \\
\hline & \multicolumn{2}{|c|}{ Aimed } & \multicolumn{2}{|c|}{ Actual } & \multirow{2}{*}{$T e_{1}$} & \multirow{2}{*}{$\mathrm{Te}_{2}$} & \multirow{2}{*}{$\Delta T e$} & \multirow{2}{*}{$t e_{1}$} & \multirow{2}{*}{$t e_{2}$} & \multirow{2}{*}{$\Delta t e$} \\
\hline & $\mathrm{La}(\mathrm{wt} \%)$ & $\mathrm{Ce}(\mathrm{wt} \%)$ & $\mathrm{La}(\mathrm{wt} \%)$ & $\mathrm{Ce}(\mathrm{wt} \%)$ & & & & & & \\
\hline T7 & 0.5 & 0.5 & 0.44 & 0.382 & 567.0 & 567.0 & 0 & 0 & 0 & 0 \\
\hline T8 & 1.0 & 1.0 & 0.78 & 0.77 & 562.72 & 563.78 & 1.05 & 296.0 & 321.6 & 25.6 \\
\hline T9 & 1.5 & 1.5 & 1.27 & 1.531 & 558.45 & 561.08 & 2.61 & 321.4 & 355.2 & 33.8 \\
\hline
\end{tabular}

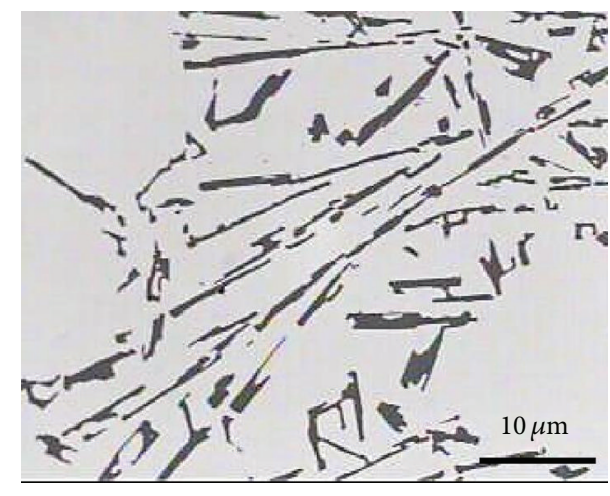

(a)

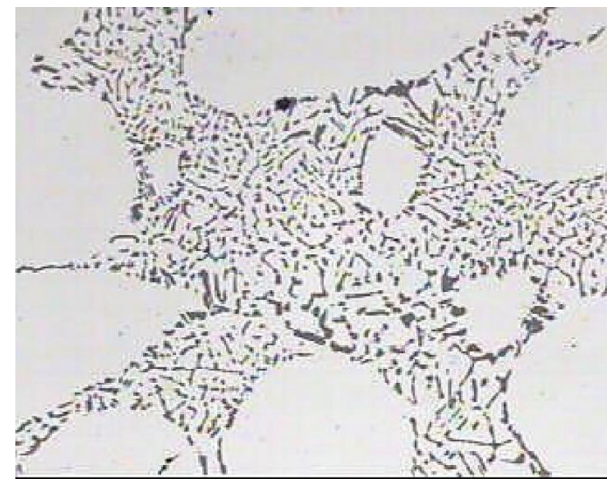

(b)

FIGURE 8: Size and distribution of eutectic Si particles in (a) T0 and (b) T0S 356 alloys.

the magnitude of the recalescence temperature $\left(\Delta T e,{ }^{\circ} \mathrm{C}\right)$ and time $(\Delta t e, \mathrm{~s})$ caused by the addition of RE to the base T0 alloy. The maximum attainable $\Delta \mathrm{Te}$ is about $2.0^{\circ} \mathrm{C}$ corresponding to $1.5 \% \mathrm{La}$. Addition of Ce seems to have a slight effect on $\Delta \mathrm{Te}$ (about $0.6^{\circ} \mathrm{C}$ ) at $1.5 \% \mathrm{Ce}$. Simultaneous addition of $1.5 \% \mathrm{La}+$ $1.5 \% \mathrm{Ce}$ increased $\Delta \mathrm{Te}$ to $2.6^{\circ} \mathrm{C}$ with an increase in $\Delta t e$ from $20 \mathrm{~s}$ to $40 \mathrm{~s}$.

3.2. Microstructural Characterization. Figures 8-11 display the eutectic Si particle size and distribution in 356 alloy. In the absence of RE elements, addition of $80 \mathrm{ppm} \mathrm{Sr}$ is sufficient to cause complete modification resulting in fine Si particle.
Addition of $\mathrm{La}, \mathrm{Ce}$, or $\mathrm{La}+\mathrm{Ce}$ is found to cause only marginal modification of the Si particles as shown in Figures 9(a), 10(a), and 11(a), respectively. The reason for such unexpected behavior is not well established. Elsebaie et al. [21-24] studied the effects of mischmetal, cooling rate, and heat treatment on the eutectic Si particle characteristics of Al-Si casting alloys. Eutectic Si particle measurements revealed that partial modification was obtained in the as-cast condition with the addition of mischmetal, while full modification was achieved with the addition of $\mathrm{Sr}$, at both high and low cooling rates. In the nonmodified alloys, the modification due to mischmetal addition was nonhomogeneous and seemed to be 


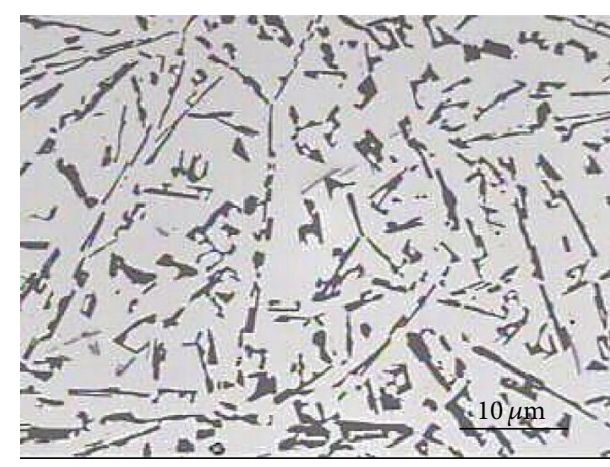

(a)

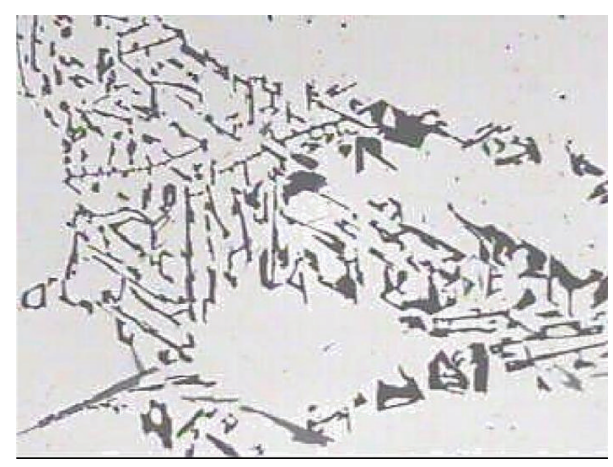

(b)

FIgURE 9: Size and distribution of eutectic Si particles in (a) T9 and (b) T9S 356 alloys.

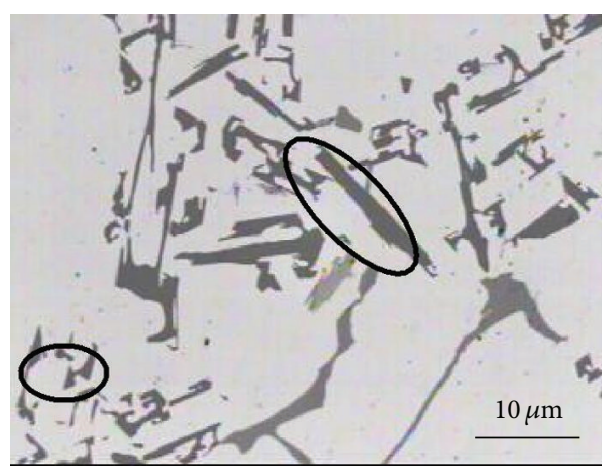

(a)

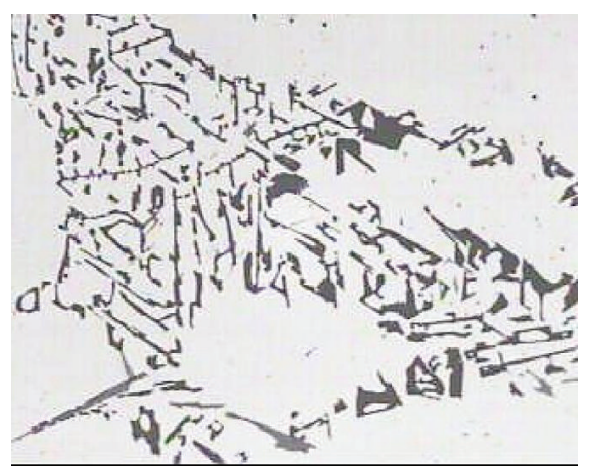

(b)

FIGURE 10: Size and distribution of eutectic Si particles in (a) T6 and (b) T6S 356 alloys.

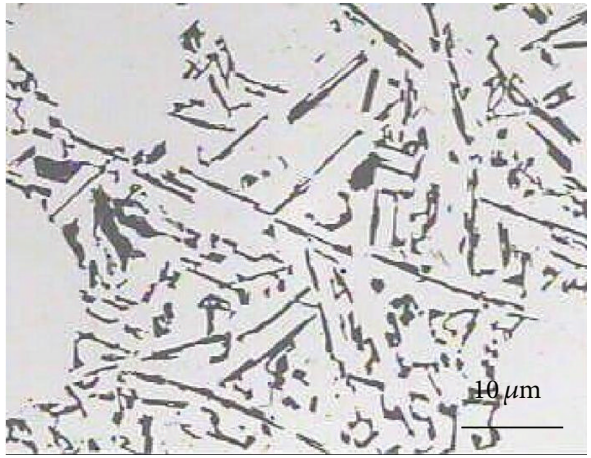

(a)

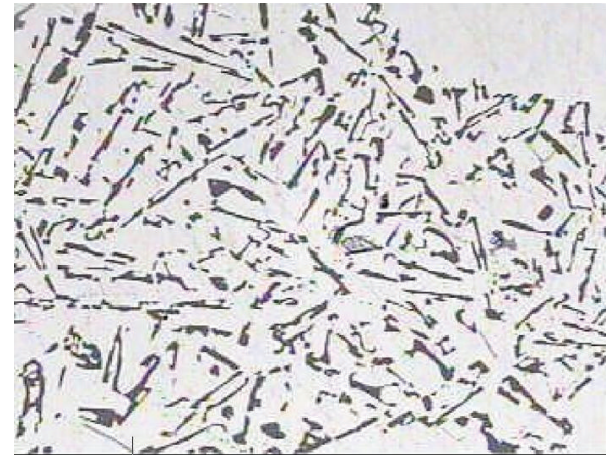

(b)

FIGURE 11: Size and distribution of eutectic Si particles in (a) T9 and (b) T9S 356 alloys.

localized around the mischmetal-containing intermetallics. In addition, the interaction between $\mathrm{Sr}$ and mischmetal was observed to weaken the effectiveness of $\mathrm{Sr}$ as a Si particle modifying agent. This effect was particularly evident at the low cooling rate and could be made clear from examining Figures 9(b), 10(b), and 11(b).

The abovementioned results are in good agreement with those of Nogita et al. [9] but in contrast to the findings of Aguirre-De la Torre et al. [27] who reported that a simultaneous refinement of both primary silicon and eutectic silicon was observed in the cast microstructure of hypereutectic Al-Si alloys through the addition of rare earth metals in the form of mischmetal. Figure 12 shows an example of $\mathrm{La}-\mathrm{Si}$ and $\mathrm{La}-\mathrm{Sr}$ interactions resulting in the formation of complex intermetallics, mainly $\mathrm{La}(\mathrm{Al}, \mathrm{Si})_{2}$ [13].

As mentioned previously [16], addition of Ce results in the formation of two intermetallics, namely, Ce-23\%Al$22 \% \mathrm{Si}$ and $\mathrm{Al}-17 \% \mathrm{Ce}-12 \% \mathrm{Ti}-2 \% \mathrm{Si}-2 \% \mathrm{Mg}$ (in wt.\%) [13]. An example of Ce-Ti interaction is shown in Figure 13, resulting 

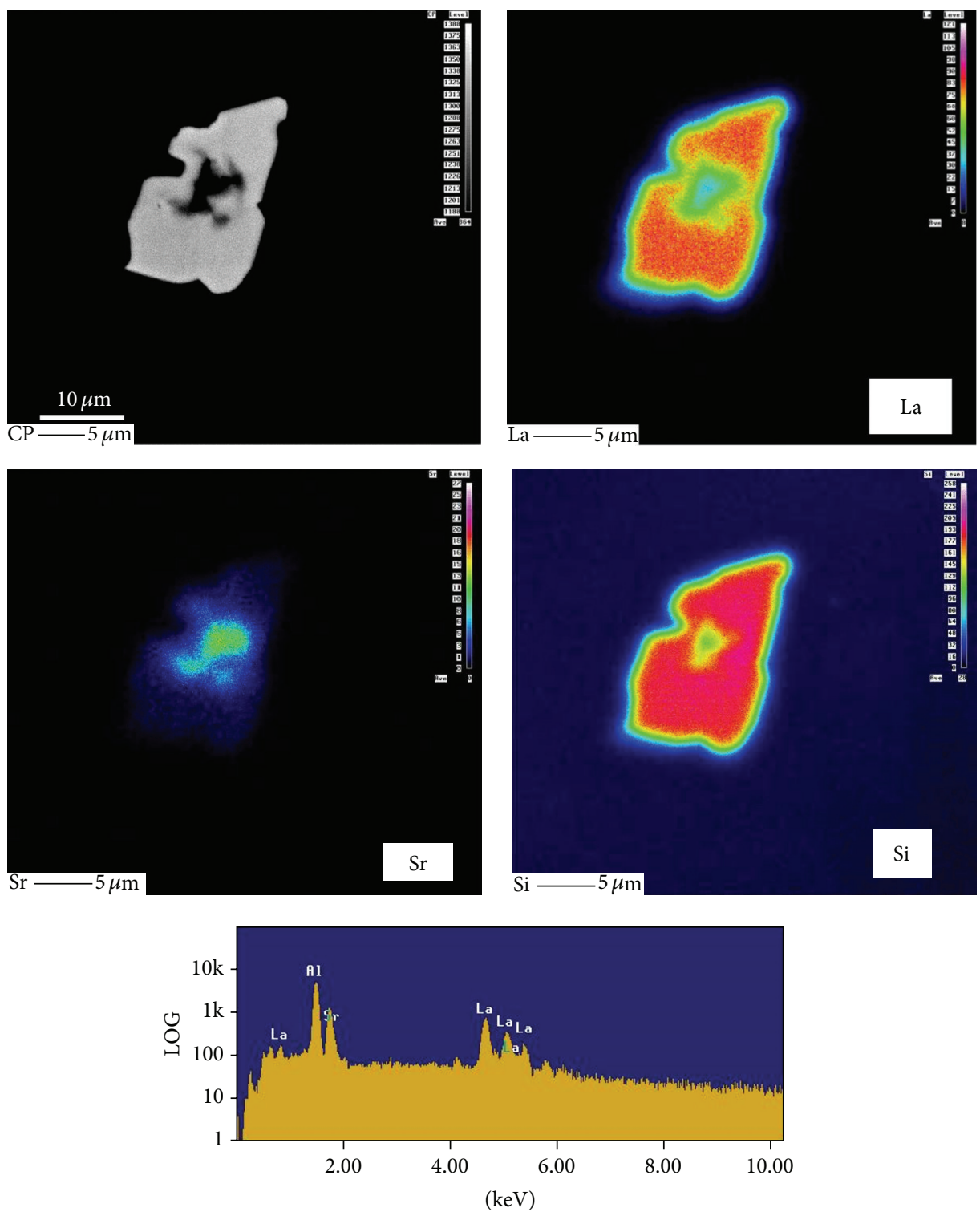

FIgURE 12: Precipitation of complex intermetallics in T3S alloy.

in massive formation of heavy sludge [20]. These intermetallics are insoluble during solution heat treatment and have been reported to cause reduction in the alloy mechanical properties [28].

Nafisi et al. [1] investigated eutectic nucleation in hypoeutectic Al-Si alloys. The nucleation mechanism of eutectic grains in hypoeutectic Al-Si foundry alloys has been investigated by examining deep etched specimens using a highresolution field emission gun scanning electron microscope (FEG-SEM). Figure 14 displays the Si particle morphology in nonmodified and Sr-modified Al-7\%Si alloys. It is evident from this figure that the particle size depends on the way in which the sample is sectioned from the casting (see the circled areas in Figure 10(a)). As a result, the use of standard deviation in these measurements is meaningless. In the present section, therefore, the average Si particle length will be used as an indicator for the effect of RE and Sr on the Si particles characteristics.
Figures 15-17 present the variation in average Si particle length with the addition of $\mathrm{RE}$ or $\mathrm{RE}+\mathrm{Sr}$ to the base alloy T0. It may be seen from these plots that addition of small amounts, for example, $0.2 \%$, of RE to the base alloy leads to partial modification. However, increasing the La content increases the Si particle average length till almost $1 \% \mathrm{La}$, beyond which a tendency for modification may be observed. Addition of Ce causes particle coarsening at all concentrations studied. The present results on Ce are in contrast to those reported by Tsaia et al. [15] who reported that the modification of the microstructure and the mechanical properties of A356 alloy are greatly enhanced by adding 1.0 wt.\% Ce. However, no explanation for the claimed Si particle refinement due to $\mathrm{Ce}$ addition was provided. Due to the high affinity of La for Sr (as was observed in Figure 12), introduction of $\mathrm{La}$ to Sr-modified alloys weakens the $\mathrm{Sr}$ modification efficiency, whence an increase in the Si particle length, as seen in Figures 15 and 17. In all cases, the average 

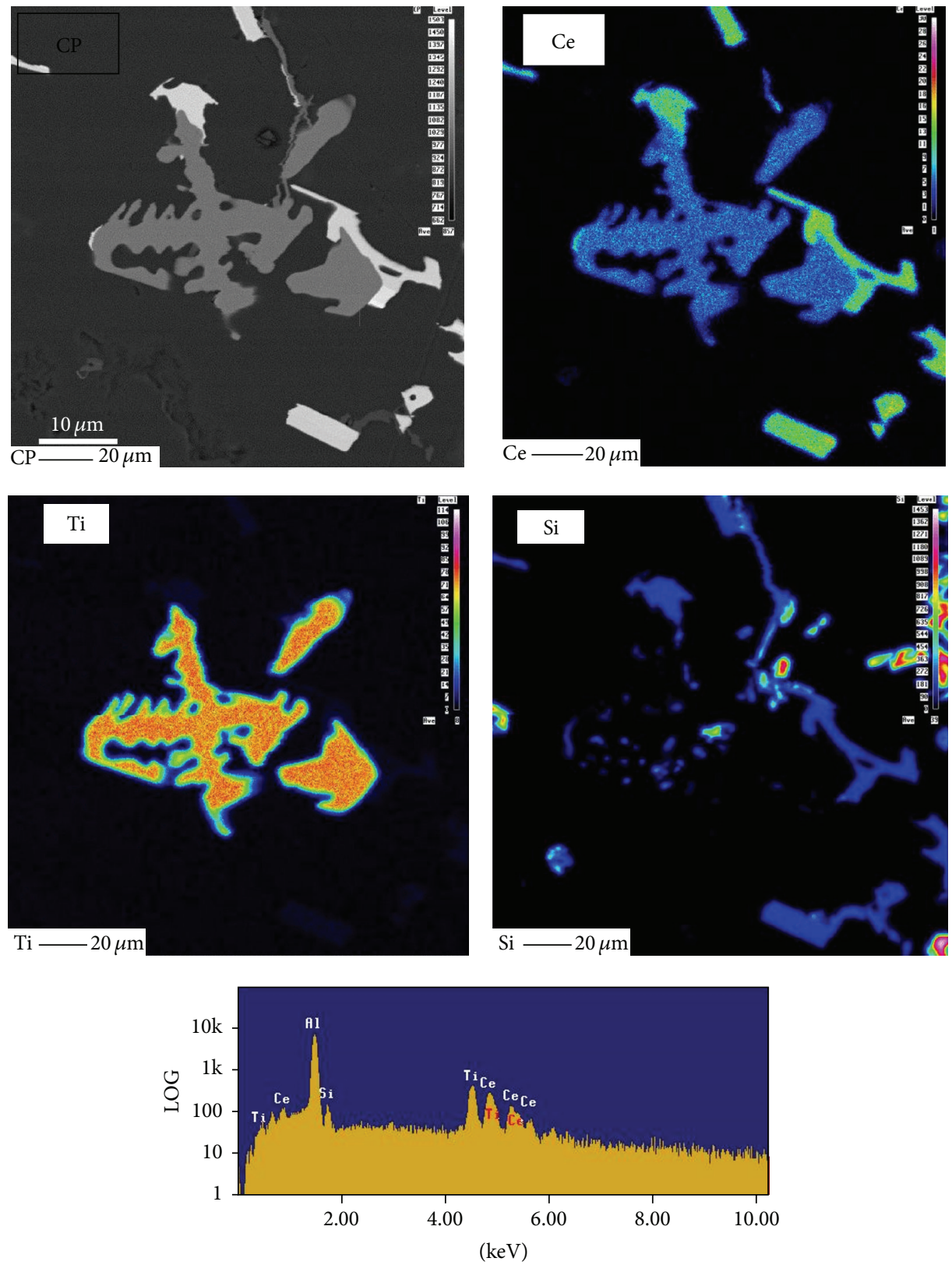

FIgURE 13: Precipitation of complex intermetallics in T6S alloy.

Si particle lengths in the Sr-modified alloys are still much smaller than those noted for the nonmodified alloys. Since Ce does not react with $\mathrm{Sr}$, no change in the Si particle length was observed when Ce was added to Sr-modified alloys as illustrated in Figure 16. It should be emphasized here that the reported behavior of $\mathrm{RE}$ metals is independent of $\mathrm{Si}$ concentration in the used alloy as shown in Figure 18 for 413 alloy.

\section{Conclusions}

Based on the results documented in the present study, the following conclusions may be drawn:
(1) From the solidification curves, it is observed that addition of La or Ce to Al-Si alloys leads to

(a) the appearance of $\mathrm{Al}-\mathrm{Si}$ recalescence $\left(2-3^{\circ} \mathrm{C}\right)$;

(b) the appearance of extra post- $\alpha$-Al peaks which may be due to precipitation of rare earth intermetallic phases.

(2) Addition of La or Ce to Al-(7-13)\%Si alloy causes only partial modification of the eutectic Si particles.

(3) Lanthanum has a high affinity to Sr which weakens the modification efficiency of Sr. 


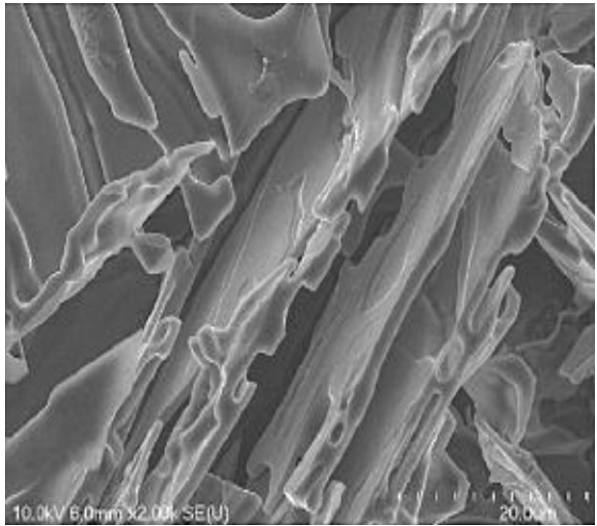

(a)

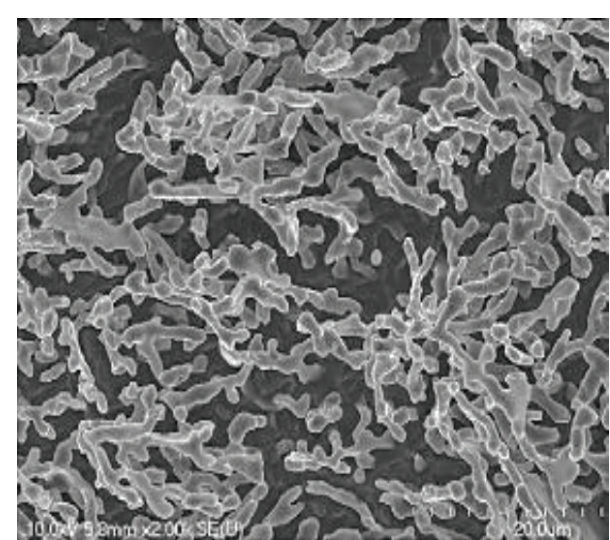

(b)

FIGURE 14: Secondary electron images of etched binary Al-7\%Si alloy samples obtained from the graphite mold: (a) nonmodified and (b) modified with 54 ppm Sr [1].

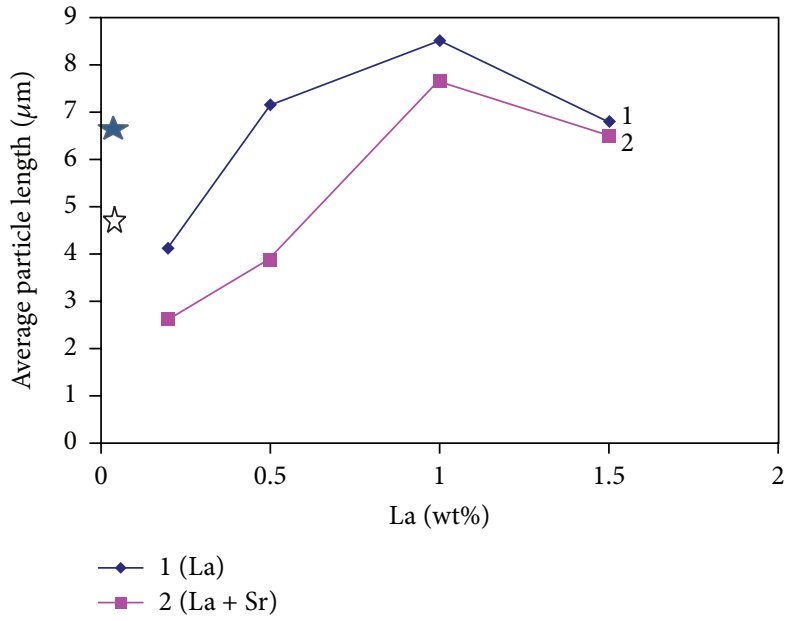

Figure 15: Effect of $\mathrm{La}$ and $\mathrm{La}+\mathrm{Sr}$ addition on the average Si particle length in 356 alloy. (Solid star: nonmodified base alloy and open star: Sr-modified base alloy.)

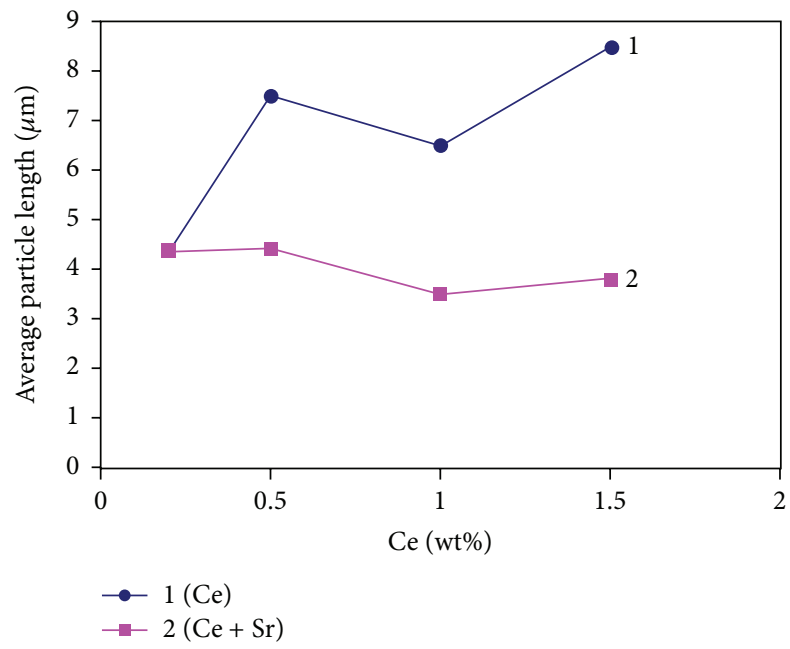

FIGURE 16: Effect of $\mathrm{Ce}$ and $\mathrm{Ce}+\mathrm{Sr}$ additions on the average $\mathrm{Si}$ particle length in 356 alloy.

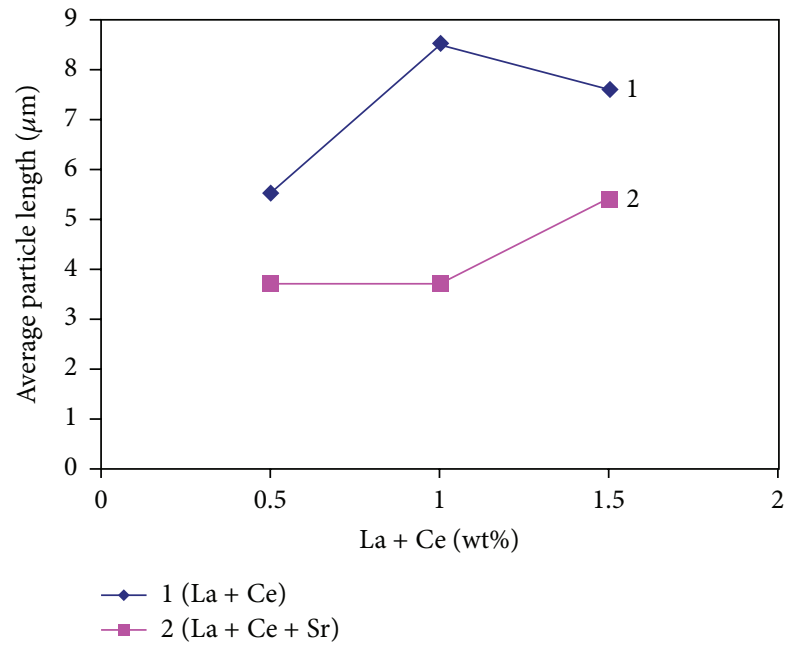

Figure 17: Effect of $\mathrm{La}+\mathrm{Ce}$ and $\mathrm{La}+\mathrm{Ce}+\mathrm{Sr}$ on the average Si particle length in 356 alloy. 


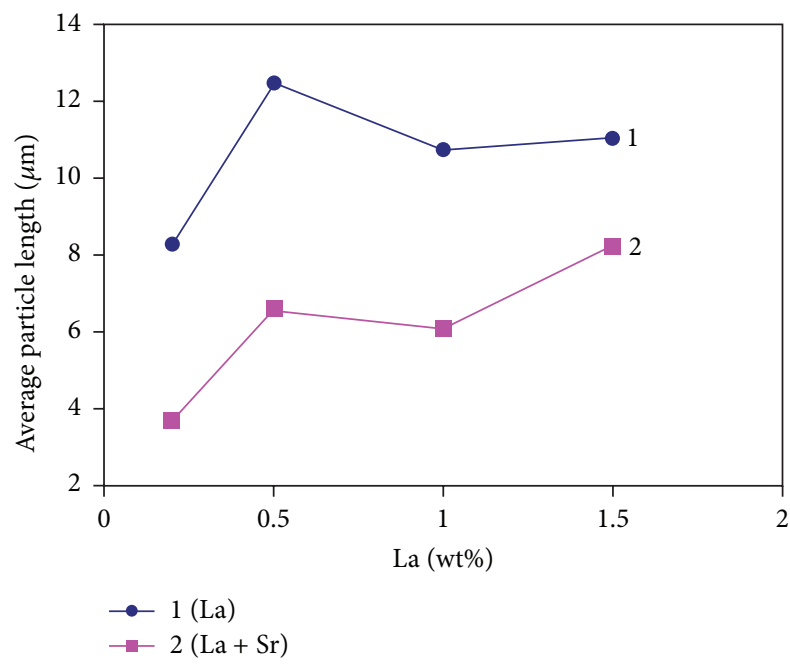

FIGURE 18: Effect of $\mathrm{La}$ and $\mathrm{La}+\mathrm{Sr}$ on the average Si particle length in 413 alloy.

(4) Ce has high affinity to $\mathrm{Ti}$, resulting in the formation of a large amount of sludge.

(5) Due the large difference in the length of the eutectic Si particles in the same sample, the normal use of standard deviation in this case is meaningless.

\section{Competing Interests}

The authors declare that there are no competing interests.

\section{Acknowledgments}

The authors would like to thank Ms. Amal Samuel for enhancing the micrographs presented in this paper.

\section{References}

[1] S. Nafisi, R. Ghomashchi, and H. Vali, "Eutectic nucleation in hypoeutectic Al-Si alloys," Materials Characterization, vol. 59, no. 10, pp. 1466-1473, 2008.

[2] K. Nogita, J. Drennan, and A. K. Dahle, "Evaluation of silicon twinning in hypo-eutectic Al-Si alloys," Materials Transactions, vol. 44, no. 4, pp. 625-628, 2003.

[3] A. Pacz, "Alloy," US Patent no. 1387900, 1921.

[4] A. K. Dahle, K. Nogita, J. W. Zindel, S. D. McDonald, and L. M. Hogan, "Eutectic nucleation and growth in hypoeutectic Al-Si alloys at different strontium levels," Metallurgical and Materials Transactions A, vol. 32, no. 4, pp. 949-960, 2001.

[5] Z.-W. Chen, X.-L. Hao, J. Zhao, and C.-Y. Ma, "Kinetic nucleation of primary $\alpha(\mathrm{Al})$ dendrites in $\mathrm{Al}-7 \% \mathrm{Si}-\mathrm{Mg}$ cast alloys with Ce and Sr additions," Transactions of Nonferrous Metals Society of China, vol. 23, no. 12, pp. 3561-3567, 2013.

[6] R. S. Rana, R. Purohit, and S. Das, "Reviews on the influences of alloying elements on the microstructure and mechanical properties of aluminum alloys and aluminum alloy composites," International Journals of Scientific Research Publications, vol. 2, pp. 1-7, 2012.
[7] A. Mazahery and M. O. Shabani, "Modification mechanism and microstructural characteristics of eutectic si in casting Al-Si Alloys: a review on experimental and numerical studies," JOM, vol. 66, no. 5, pp. 726-738, 2014.

[8] M. Malekan, D. Dayani, and A. Mir, "Thermal analysis study on the simultaneous grain refinement and modification of 380.3 aluminum alloy," Journal of Thermal Analysis and Calorimetry, vol. 115, no. 1, pp. 393-399, 2014.

[9] K. Nogita, S. D. McDonald, J. W. Zindel, and A. K. Dahle, "Eutectic solidification mode in sodium modified Al-7 mass\% Si-3.5 mass\% Cu-0.2 mass\% Mg casting alloys," Materials Transactions, vol. 42, no. 9, pp. 1981-1986, 2001.

[10] L. Hengcheng, B. Juanjuan, Z. Min, D. Ke, J. Yunfeng, and C. Mingdong, "Effect of strontium and solidifi cation rate on eutectic grain structure in an Al-13 wt\% Si alloy," China Foundry, vol. 6, no. 3, pp. 226-231, 2009.

[11] K. Nogita, S. D. McDonald, and A. K. Dahle, "Eutectic modification of Al-Si alloys with rare earth metals," Materials Transactions, vol. 45, no. 2, pp. 323-326, 2004.

[12] B. Pourbahari, M. Emamy, M. Lotfpour, and S. H. Allameh, "Effects of La intermetallics on the structure and tensile properties of thin section gravity die-cast A357 Al alloy," in Proceedings of the International Conference on Chemical, Metallurgy and Environmental Engineering (ICMAEE '15), pp. 296-303, Istanbul, Turkey, June 2015.

[13] M. Hosseinifar and D. V. Malakhov, "Effect of Ce and La on microstructure and properties of a 6xxx series type aluminum alloy," Journal of Materials Science, vol. 43, no. 22, pp. 7157-7164, 2008.

[14] M. Hosseinifar and D. V. Malakhov, "The sequence of intermetallics formation during the solidification of an Al-Mg-Si alloy containing La," Metallurgical and Materials Transactions A, vol. 42, no. 3, pp. 825-833, 2011.

[15] Y. Tsaia, S. Leeab, and C. Lin, "Effect of trace Ce addition on the microstructures and mechanical properties of A356 (AL7SI-0.35 Mg) aluminum alloys," Journal of the Chinese Institute of Engineers, vol. 34, no. 5, pp. 609-616, 2011.

[16] M. Song, D. Xiao, and F. Zhang, "Effect of Ce on the thermal stability of the $\Omega$ phase in an Al-Cu-Mg-Ag alloy," Rare Metals, vol. 28, no. 2, pp. 156-159, 2009.

[17] L. A. Dobrzański, R. Maniara, and J. H. Sokolowski, "Structure analysis of Al cast alloy," Journal of Achievements in Materials and Manufacturing Engineering, vol. 17, pp. 217-220, 2006.

[18] R. Aparicio, G. Barrera, G. Trapaga, M. Ramirez-Argaez, and C. Gonzalez-Rivera, "Solidification kinetics of a near eutectic Al-Si alloy, unmodified and modified with Sr," Metals and Materials International, vol. 19, no. 4, pp. 707-715, 2013.

[19] J. L. Murray and A. J. McAlister, “The Al-Si (Aluminum-Silicon) system," Bulletin of Alloy Phase Diagrams, vol. 5, pp.77-84, 1984.

[20] L. Bäckerud, G. Chai, and J. Tamminen, Solidification Characteristics of Aluminum Alloys, Volume 2: Foundry Alloys, AFS/Skanaluminium, Des Plaines, Ill, USA, 1990.

[21] O. Elsebaie, F. H. Samuel, and S. Al Kahtani, "Intermetallic phases observed in nonmodified and Sr modified Al-SI cast alloys containing mischmetal," International Journal of Cast Metals Research, vol. 26, no. 1, pp. 1-15, 2013.

[22] O. Elsebaie, A. M. A. Mohamed, A. M. Samuel, F. H. Samuel, and A. M. A. Al-Ahmari, "The role of alloying additives and aging treatment on the impact behavior of 319 cast alloy," Materials and Design, vol. 32, no. 6, pp. 3205-3220, 2011. 
[23] O. Elsebaie, A. M. Samuel, and F. H. Samuel, "Effects of Srmodification, iron-based intermetallics and aging treatment on the impact toughness of $356 \mathrm{Al}-\mathrm{Si}-\mathrm{Mg}$ alloy," Journal of Materials Science, vol. 46, no. 9, pp. 3027-3045, 2011.

[24] Y. Han, A. M. Samuel, H. W. Doty, S. Valtierra, and F. H. Samuel, "Optimizing the tensile properties of $\mathrm{Al}-\mathrm{Si}-\mathrm{Cu}-\mathrm{Mg}$ 319-type alloys: role of solution heat treatment," Materials and Design, vol. 58, pp. 426-438, 2014.

[25] D. Ferdian, J. Lacaze, I. Lizarralde, A. Niklas, and A. I. Fernández-Calvo, "Study of the effect of cooling rate on eutectic modification in A356 aluminium alloys," Materials Science Forum, vol. 765, pp. 130-134, 2013.

[26] L. F. Mondolfo, Aluminum Alloys, Structure and Properties, Butterworth, London, UK, 1979.

[27] E. Aguirre-De la Torre, R. Pérez-Bustamante, J. CamarilloCisneros, C. D. Gómez-Esparza, H. M. Medrano-Prieto, and R. Martínez-Sánchez, "Mechanical properties of the A356 aluminum alloy modified with La/Ce," Journal of Rare Earths, vol. 31, no. 8, pp. 811-816, 2013.

[28] H. M. Medrano-Prieto and R. Martinez-Sanchez, "Mechanical properties of the A356 aluminum alloy modified with La/Ce," Journal of Rare Earths, vol. 31, no. 8, pp. 811-816, 2013. 

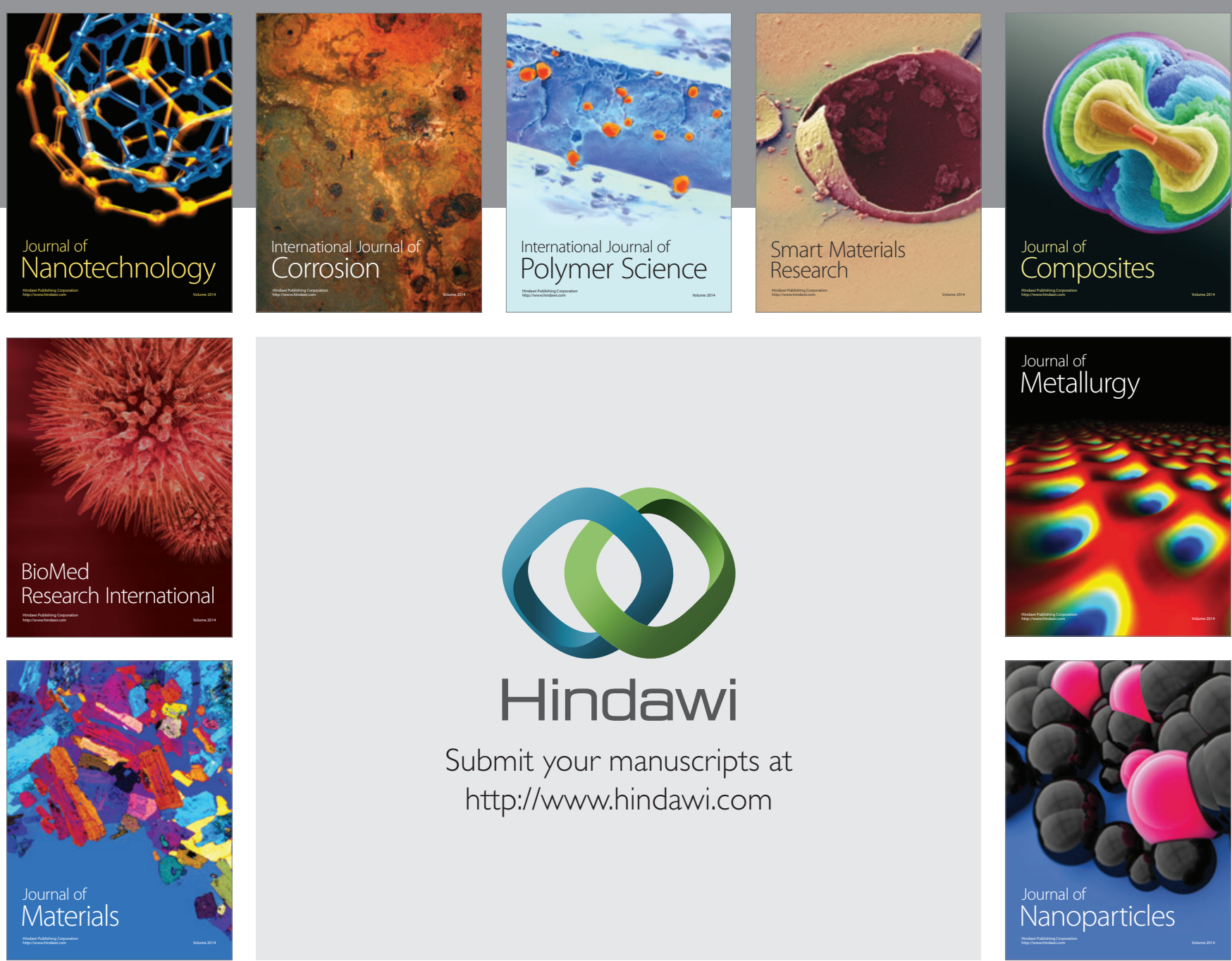

\section{Hindawi}

Submit your manuscripts at

http://www.hindawi.com

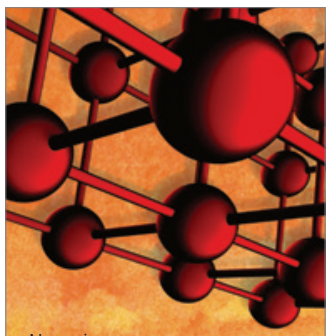

Materials Science and Engineering
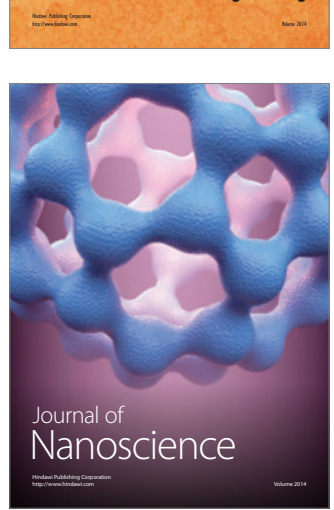
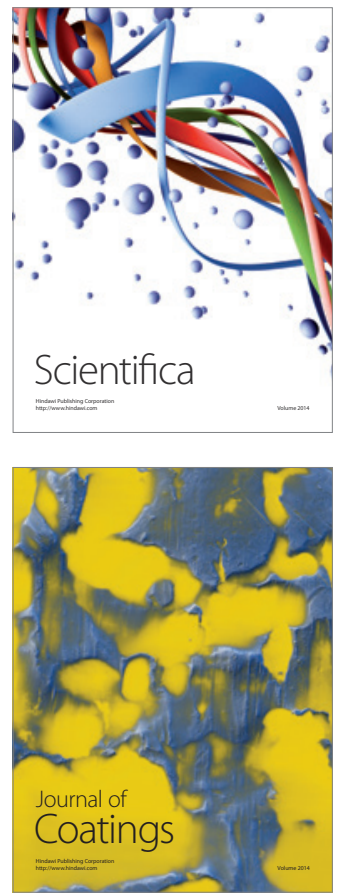
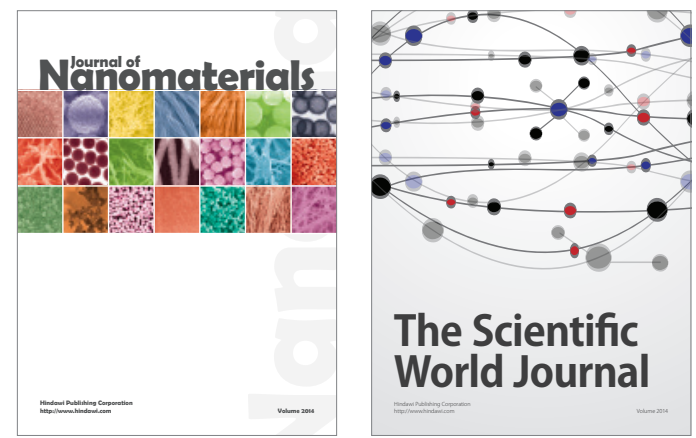

The Scientific World Journal
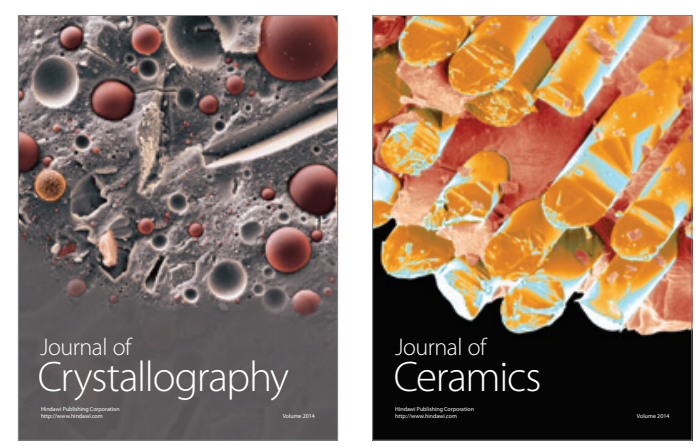
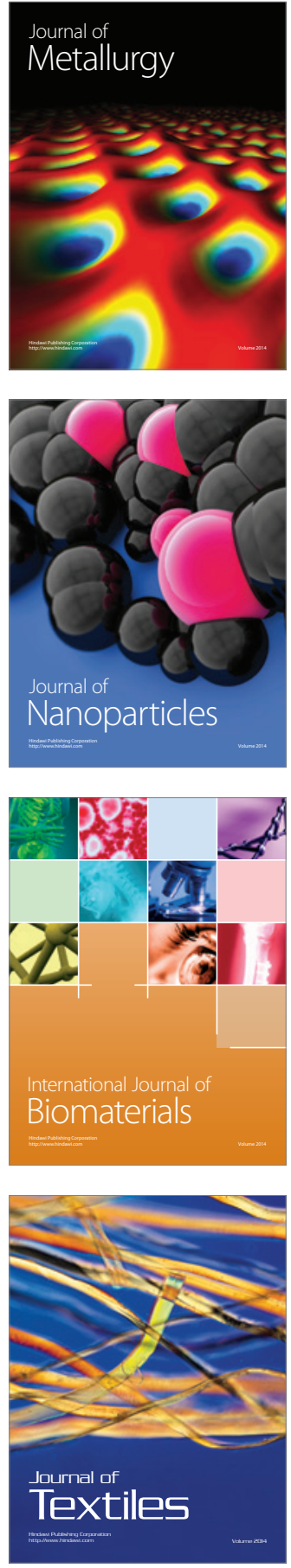